\title{
Nosocomial and community infections due to class A extended-spectrum $\beta$-lactamase (ESBLA)-producing Escherichia coli and Klebsiella spp. in southern Brazil
}

\section{Authors}

Claudia Wollheim ${ }^{1}$

Ivani Maria F Guerra ${ }^{2}$

Vania D Conte ${ }^{3}$

Sheila P Hoffman ${ }^{3}$

Fernando J Schreiner

Ana Paula L Delamare

Afonso L Barth ${ }^{5}$

Sérgio Echeverrigaray ${ }^{6}$

Sérgio Olavo P da Costa ${ }^{6}$

${ }^{1} \mathrm{PhD}$, Medical

Microbiology Laboratory,

Universidade de Caxias do

Sul, RS, Brazil

${ }^{2}$ MS; Medical Microbiology

Laboratory, Universidade

de Caxias do Sul, RS, Brazil

${ }^{3}$ Pharmacist; Medical

Microbiology Laboratory,

Universidade de Caxias do

Sul, RS, Brazil

${ }^{4} \mathrm{PhD}$,Instituto de

Biotecnologia, Universidade

de Caxias do Sul, RS, Brazil

${ }^{5} \mathrm{PhD}$, Hospital de Clínicas

de Porto Alegre, RS, Brazil

${ }^{6} \mathrm{PhD}$, Instituto de

Biotecnologia, Universidade

de Caxias do Sul, RS, Brazil
Submitted on: 06/12/2010 Approved on: 09/29/2010

\section{Correspondence to:}

Cláudia Wollheim

Laboratório de

Microbiologia Médica

Humana

Universidade de Caxias do Sul

Rua Francisco Getúlio Vargas, 1130, Petrópolis, Caxias do Sul, RS, Brazil 95001-970

Phone: + 5554 3218-2548

Fax: + 5554 3218-2041

cwollhei@ucs.br

We declare no conflict of interest.

\begin{abstract}
Objectives: To determine the prevalence of class A extended spectrum $\beta$-lactamases (ESBL)-producing Escherichia coli and Klebsiella spp., and to investigate clonality among ESBL-producing isolates of nosocomial and community infections. Methods: The study involved 354 nosocomial infections samples and 992 community infections samples, obtained between 2003 and 2006 at Caxias do Sul, RS. The detection of ESBL was performed by the disk-diffusion test. Presence of $b l a_{\text {СтX-M, }}$, $b l a_{\mathrm{SHV}}$ and $b l a_{\mathrm{TEM}} \beta$-lactamase genes was evaluated by PCR, and genomic typing was determined by pulsed-field gel electrophoresis analysis. Results: Higher frequency of ESBL-producing isolates were detected among nosocomial samples of E. coli (6.7\%) and Klebsiella (43.7\%), than those obtained from community infections $(0.4 \%$ and $2.6 \%) . b l a_{\text {TEM }}$ and $b l a_{\text {СТX }}$ were the most prevalent ESBL gene families in both E. coli and Klebsiella isolates. Different pulsotypes were obtained among ESBL-producing E. coli and 11 clones for Klebsiella spp., which occurred over the years and in different hospital wards. Among ESBL-producing K. pneumoniae, 74.3\% transferred ESBL genes by conjugation and exhibited concomitant decreased aminoglycosides susceptibility. Conclusion: ESBL-producing E. coli, and especially K. pneumoniae are essentially a nosocomial problem, and their dissemination to the community is relatively limited. The great genetic variability observed among ESBL-producing bacteria indicates polyclonal spread and high transference of ESBL genes between bacteria in the hospital environment. This information is of paramount importance for nosocomial infection control.
\end{abstract}

Keywords: $\beta$-lactamases; polymerase chain reaction; bacterial typing techniques.

[Braz J Infect Dis 2011;15(2):138-143]@Elsevier Editora Ltda.

\section{INTRODUCTION}

Extended-spectrum $\beta$-lactamase-producing clinical isolates among members of the Enterobacteriaceae family, especially Klebsiella pneumoniae and Escherichia coli, represent one of the most important world problems of $\beta$-lactam antimicrobial resistance, commonly used in the treatment of many bacterial nosocomial and community infections. ${ }^{1}$

Traditionally ESBLs appeared just after the introduction of third-generation cephalosporins, and evolved from parent enzymes due to point mutation in the $b l a_{\mathrm{TEM}-1 / 2}$ and $b l a_{\mathrm{SHV}-1}$ genes around the $\beta$-lactamase active site. ${ }^{2}$ The majority of ESBLs belong to the functional class 2 be/molecular class A, particularly TEM and SHV types, and the CTX-M family $\beta$-lactamases encoded by genes captured by mobile elements from the chromosomes of the environmental bacteria Kluyvera spp. ${ }^{1}$
At present, the definition of ESBL as 2be/ molecular class A, clavulanic acid inhibited enzymes that cause resistance to penicillins, to all cephalosporin generations, and to the monobactam aztreonam, but not to cephamycins or carbapenems, is narrow and excludes other clinically important acquired $\beta$-lactamase with wider spectrum. ${ }^{1}$ In the effort to prevent the spread of acquired $\beta$-lactamase, a new classification had been proposed including $\beta$-lactamase with activity against extended-spectrum cephalosporins and/or carbapenems, making the classification more accessible to clinicians, infection control professionals, hospital managers, and politicians. Three groups of ESBL were projected: (1) $\mathrm{ESBL}_{\mathrm{A}}$ (classical class A ESBLs); (2) $\mathrm{ESBL}_{\mathrm{M}}$ (plasmid-mediated AmpC and OXA-ESBLs classedw as miscellaneous ESBLs); and (3) ESBL $_{\text {CARBA }}$ (carbapenemases). ${ }^{1,3}$ 
The correct identification of ESBL-producing bacteria has important clinical-epidemiological and laboratory implications. First, patients may experience a delay in appropriate treatment if ESBL-producing bacteria are not correctly detected by routine antimicrobial susceptibility tests. ${ }^{4}$ Second, while carbapenemics are the most effective therapy for ESBL bacterial infections, their routine use can select resistant strains, as the emergence of imipenem-resistant Acinetobacter baumanii, Pseudomonas aeruginosa and K. pneumoniae. ${ }^{5,6}$ Third, ESBL genes are located on large plasmids that can harbor genes for resistance to other non- $\beta$-lactams antibiotics, and therefore, ESBL-producing bacteria often exhibit multidrug-resistant phenotypes, reducing the drug arsenal even further. ${ }^{1}$ Fourth, genes encoding ESBLs are typically located in conjugative plasmids or integron-like structures and can be effectively transferred to other strains and species. ${ }^{7,8}$ Finally, ESBL-producing organisms, especially K. pneumoniae, but also E. coli, have been responsible for serious nosocomial infection outbreaks that lead to prolonged hospital stay, increased morbidity and mortality, and consequently increase healthcare associated costs. ${ }^{9-11}$

Since the first description of ESBL in 1983, in Germany, ESBL-producing clinical isolates have spread rapidly throughout Europe and the United States and are now disseminated worldwide. ${ }^{12,13}$ However, the world prevalence of ESBL producers varies greatly, even among health institutions in the same country. ${ }^{14}$ Although it is a major threat for patients in the hospital, currently ESBL are becoming an emerging problem for patients in long-term care facilities, and also in the community in some areas of the world. ${ }^{15-17}$

The aims of this study were to determine the prevalence of ESBL among E. coli and Klebsiella spp. in Caxias do Sul, in the southern region of Brazil, to identify the prevalence of $\beta$-lactamase genes $\left(b l a_{\mathrm{TEM}}, b l a_{\mathrm{SHV}}\right.$ and $\left.b l a_{\mathrm{CTX}-\mathrm{M}}\right)$, and to investigate clonality among clinical isolates of ESBL-producing E. coli and Klebsiella spp. of nosocomial and community infections during a period of three years.

\section{MATERIAL AND METHODS}

\section{Patient population and definitions}

The study was carried between April 2003 and May 2006 at a private clinical analyses laboratory, and at the General Hospital of Caxias do Sul (HG), located in Rio Grande do Sul State Brazil. The HG is a 257-bed public university teaching hospital and acts as a referral hospital for a wider area of Northeast RS, covering a population of about one million inhabitants. Personal data (age, sex), type of specimens, and the hospital ward at the HG where the patient had been assigned were obtained. Nosocomial infection was defined as infection which occurred more than 48 hours after hospital admission; infection which occurred less than 48 hours af- ter hospital admission, if that patient had been hospitalized within the prior 30 days; or infection which occurred in a patient transferred from another hospital or from a nursing home. ${ }^{18}$ Patients with community infection were those presenting it at a community clinical analyses laboratory and those who had a positive culture at the time of or within 48 hours of hospitalization; in both cases, patients had no previous contacts with hospitals or long-term care facility in the previous two weeks. ${ }^{19}$

\section{Bacterial isolates}

Clinical specimens obtained from patients with nosocomial infection yielded 354 isolates (209 E. coli, $142 \mathrm{~K}$. pneumoniae and $3 \mathrm{~K}$. oxytoca), and a total of 992 isolates (953 E. coli, $38 \mathrm{~K}$. pneumoniae and $1 \mathrm{~K}$. oxytoca) were obtained from patients with community infection. Isolates were identified using the conventional biochemical tests and stored at $-70^{\circ} \mathrm{C}$ in skim milk. Only one isolate from each patient was included in the study.

\section{Screening and confirmation tests of ESBLs}

ESBL-producing isolates identification was made by the disk-diffusion screening test with aztreonam, cefotaxime, ceftazidime, ceftriaxone, and cefpodoxime, followed by a confirmatory test with ceftazidime and cefotaxime, combined with clavulanic acid as recommended by the Clinical and Laboratory Standards Institute (CLSI). ${ }^{20} \mathrm{An}$ additional confirmatory test was performed with cefepime and cefpodoxime discs containing clavulanic acid. All the tests were conducted with Oxoid antibiotic discs. The standard strains E. coli ATCC 25922 and K. pneumoniae ATCC 700603 were used as negative and positive controls of ESBLs production.

\section{PCR amplification for detection of $\beta$-lactamase genes}

The bacterial isolates with confirmed ESBL phenotype were submitted to PCR assay to identify $b l a_{\mathrm{CTX}-\mathrm{M}}, b l a_{\mathrm{SHV}}$ and bla тем $\beta$-lactamase genes, using the primers and method described by Paterson et al. ${ }^{14}$ The K. pneumoniae ATCC 700603 strain was used as a positive control for the blaSHV gene.

\section{Molecular typing}

Genomic typing of ESBL producing isolates was performed by the pulsed-field gel electrophoresis (PFGE) technique based on PulseNet PFGE protocol..$^{21}$ Briefly, genomic DNA was prepared in agarose plugs, cut with restriction endonuclease SpeI (Invitrogen), and restriction fragments separated using a CHEF-DRIII system (Bio-Rad). Photographs of ethidium bromide-stained gels were examined visually and the macrorestriction patterns were interpreted according to the criteria proposed by Tenover et al. ${ }^{22} \mathrm{~A} 48.5 \mathrm{~Kb}$ bacteriophage $\lambda$ ladder was used as a DNA size marker. 


\section{Gene transfer assays}

Conjugation assays were carried out by a broth mating procedure in Lurian-Bertani (LB) broth with 35 ESBL-producing $K$. pneumoniae isolates susceptible to streptomycin and ceftriaxone. DH5a E. coli (streptomycin resistant, lactose fermentation negative, and plasmid free) was used as the recipient. ${ }^{23}$ Overnight cultures of donor and recipient strains grown in LB broth were added to $8 \mathrm{~mL}$ of fresh LB broth at a donor-recipient ratio of 1:1 (300 $\mu \mathrm{L}$ of cultures each), and incubated for 4 hours at $37^{\circ} \mathrm{C}$. The mixed culture was plated onto MacConkey agar containing $30 \mu \mathrm{g} / \mathrm{mL}$ of ceftriaxone and $300 \mu \mathrm{g} / \mathrm{mL}$ of streptomycin. Six colonies growing on the selections plates and again on subculture on selective MacConkey agar were subjected to confirmatory tests of ESBLs and to antimicrobial susceptibility by disk diffusion assays according to CLSI recommendation with amikacin, gentamicin, tobramicin, ciprofloxacin, gatifloxacin, nitrofurantoin, trimethoprim/sulfamethoxazole and chloramphenicol. Resistance was considered nontransferable when the isolates failed to transfer in more than two experiments.

\section{RESULTS}

\section{Prevalence of ESBL isolates}

A total of 1,346 non-replicated isolates (354 from nosocomial and 992 from community infection patients) were analyzed. Overall, $21.8 \%$ (77/354) and $0.5 \%$ (5/992) of the isolates were confirmed as ESBL producers by the clavulanic acid inhibition disk diffusion assay. Fourteen (6.7\%) of 209 patients with E. coli infection had ESBL-producing strain, compared with 4 (0.4\%) of 953 patients with community-acquired $E$. coli infection. ESBL-producing K. pneumoniae were isolated from $62(43.7 \%)$ of 142 patients with nosocomial infection, and from one (2.6\%) of 38 isolates with community-acquired infection. Among the four $\mathrm{K}$. oxytoca isolates, one obtained from a nosocomial patient exhibited ESBL phenotype (Table 1).

Table 1. Prevalence of ESBL-positive Escherichia coli and Klebsiella spp. by origin of the infection

\begin{tabular}{|c|c|c|c|}
\hline \multirow{2}{*}{$\begin{array}{l}\text { Origin in } \\
\text { infection } \\
\text { species }\end{array}$} & \multirow{2}{*}{$\begin{array}{c}\text { Total no. } \\
\text { of isolates } \\
(n=1,346)\end{array}$} & \multicolumn{2}{|c|}{ ESBL positive isolates } \\
\hline & & $\begin{array}{l}\text { No. of } \\
\text { isolates }\end{array}$ & $\begin{array}{c}\% \text { in } \\
\text { species }\end{array}$ \\
\hline \multicolumn{4}{|l|}{ Nosocomial } \\
\hline E. coli & 209 & 14 & 6.7 \\
\hline К. рпеитопіае & 142 & 62 & 43.7 \\
\hline K. oxytoca & 3 & 1 & 33.3 \\
\hline Total & 354 & 77 & 21.8 \\
\hline \multicolumn{4}{|l|}{ Community } \\
\hline E. coli & 953 & 4 & 0.4 \\
\hline K. pneumoniae & 38 & 1 & 2.6 \\
\hline K. oxytoca & 1 & 0 & 0 \\
\hline Total & 992 & 5 & 0.5 \\
\hline
\end{tabular}

\section{Patient population and source of specimens}

Of the 1,346 patients studied, the mean age and gender of patients with nosocomial infection were different among those with community infections $(51.4 \pm 28.0$ years and $54.8 \%$ female versus $39.1 \pm 22.4$ years and $89.3 \%$ female). In both patient populations, the most frequent source of infection was urinary. The high frequency of urinary infections (97.7\%) among community patients explains the difference on gender proportion. The mean age of the patients with nosocomial infection due to ESBL-producing E. coli and Klebsiella spp. differed significantly ( $40.7 \pm 31.7$ years, range: 8.3 months to 88 years versus $4.8 \pm 2.9$ years, range: 4 days to 92 years), respectively. Most patients (65.1\%) with nosocomial infection due to ESBL-producing Klebsiella spp. were male, while no gender difference was observed among community infection patients.

The ESBL-producing bacteria obtained from patients with nosocomial infections were isolated from the urinary tract (5.8\% E. coli and 49\% Klebsiella spp.), respiratory tract (14.3\% E. coli and $41.9 \%$ Klebsiella spp.), blood/catheter (12.5\% E. coli and $48.4 \%$ Klebsiella spp.), peritoneal liquid (25\% Klebsiella spp.), and skin/soft tissue (25\% Klebsiella spp.). Most ESBLproducers were detected on patients hospitalized in IntensiveCare Units, including the Neonatal, Pediatric and Adult ICUs (15.9\% E. coli and 51.7\% Klebsiella spp.), in Clinical-Surgical Units (4.3\% E. coli and 45.5\% Klebsiella spp.), and Urgency and Emergency wards (31.6\% Klebsiella spp.).

\section{Prevalence of $\boldsymbol{\beta}$-lactamase genes and genotyping}

As shown in Figure 1, 61.1\% of ESBL-producing E. coli were isolated during 2005 to 2006 , whereas $67.2 \%$ of ESBL Klebsiella spp. isolates were collected between 2003 to 2004.

The PCR assay allowed detection of $b l a_{\text {TEM }}$ gene family in $66.7 \%$ of the isolates of ESBL-producing E. coli, followed by $b l a_{\text {CTX-M }}$ gene $(50 \%)$ and the $b l a_{\mathrm{SHV}}$ gene $(11.1 \%)$ (Figure 1A). Several E. coli isolates exhibited $\beta$-lactamase gene combinations (bla $a_{\mathrm{CTX}-\mathrm{M}}$ and $b l a_{\mathrm{SHV}}, b l a_{\mathrm{CTX}-\mathrm{M}}$ and $\left.b l a_{\mathrm{TEM}}\right)$, and no amplification products were observed in one ESBL isolate. Among Klebsiella spp. with ESBLphenotype, $b l a_{\text {TEM }}$ gene was the most prevalent (95.3\%), followed by the $b l a_{\text {СТХ-M }}(82.8 \%)$, and the blaSHV gene $(42.2 \%)$ (Figure 1B). Combination of two and three ESBL genes was detected in $59.4 \%$ and $31.3 \%$ of ESBL-producing Klebsiella isolates.

The clonal relatedness was studied by PFGE. Eighteen different pulsotypes were obtained among 18 ESBLproducing $E$. coli isolates, and 23 pulsotypes among 63 ESBL-producing $K$. pneumoniae (Figure 1). One isolate was consistently untypeable by the applied method.

Genotyping revealed that $82.3 \%$ of K. pneumoniae isolated were non-unique and could be separated into 11 clones. The most prevalent (Clone 5) with 13 isolates, 
emerged in 2003 with four isolates in two hospital wards (Clinical-Surgical floor 5 and Adult ICU floor 3), and was detected again in 2004, with 9 isolates recovered from the same hospital wards. The occurrence of different clones over the years and hospital wards are shown in Table 2.
Among the 35 ESBL-producing K. pneumoniae isolates selected for conjugation experiments, $74.3 \%$ (26 isolates) transferred ESBL genes by conjugation. All donor strains harbored the $b l a_{\text {CTX-M }}$ gene. The transconjugants obtained exhibited decreased susceptibilities to the aminoglycosides, amikacin, gentamicin and tobramicin.

Figure 1: Distribution of different $\beta$-lactamase genes among ESBL-positive 18 E. coli (A) and 64 Klebsiella spp. (B) isolates from 2003 to 2006. Values between brackets represent the number of pulsotypes.
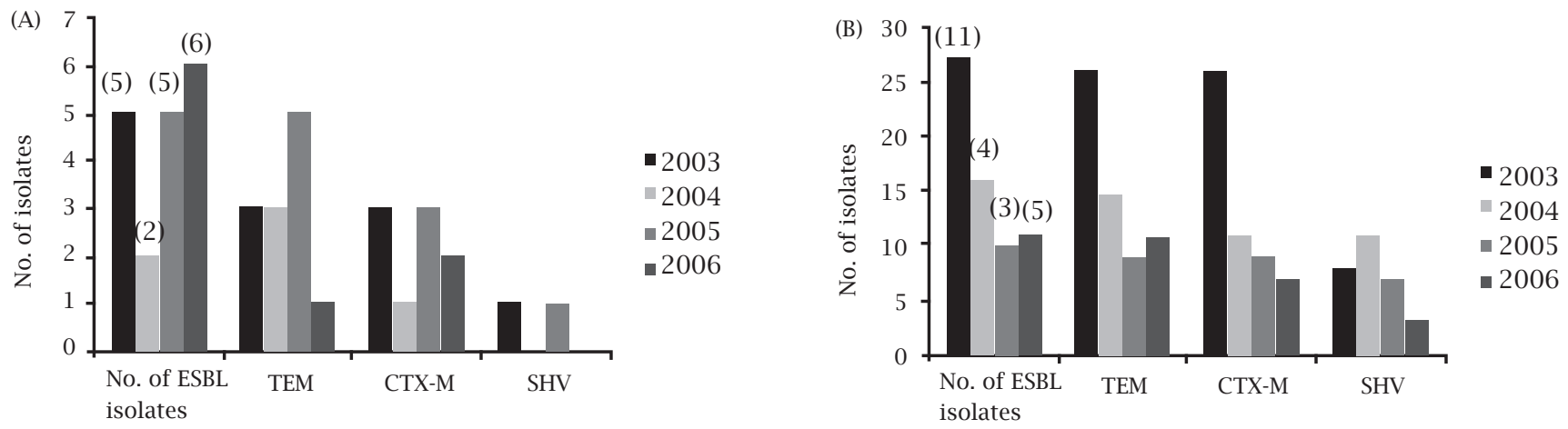

Table 2. Distribution of the 11 clones of ESBL-producing Klebsiella pneumoniae by genes of $\beta$-lactamases, time of detection the isolates and hospital ward

\begin{tabular}{|c|c|c|c|c|c|c|c|}
\hline $\begin{array}{l}\text { PFGE } \\
\text { type }\end{array}$ & $\begin{array}{l}\mathrm{N}^{0} \text { of } \\
\text { isolates }\end{array}$ & $\frac{\beta \text {-lacmatas }}{\text { CTX-M }}$ & $\begin{array}{l}\text { se genes } \\
\text { TEM }\end{array}$ & $\frac{\text { profile }^{\mathrm{a}}}{\text { SHV }}$ & $\begin{array}{c}\text { Time (yr) } \\
\text { of isolation }\end{array}$ & $\begin{array}{l}\text { Hospital ward of isolation } \\
\text { (No. of isolates) }\end{array}$ & Floor \\
\hline \multirow[t]{3}{*}{ Clone 1} & 4 & + & + & - & 2003 & Clinical-surgical (1) & $6^{\circ}$ \\
\hline & & + & + & + & $2003 / 2005$ & Clinical-surgical (1)/b & $6^{\circ}$ \\
\hline & & - & + & + & 2006 & Adult ICU (1) & $3^{\circ}$ \\
\hline \multirow[t]{2}{*}{ Clone 2} & 6 & + & + & - & 2003 & Neonatal ICU (2), clinical-surgical (2) & $3^{\circ}, 6^{\circ}$ \\
\hline & & + & + & - & 2003 & Urgency-emergency (1), clinical-surgical (1) & $1^{\circ}, 5^{\circ}$ \\
\hline \multirow[t]{2}{*}{ Clone 3} & 5 & + & + & - & 2003 & Neonatal ICU (2), adult ICU (1) & $3^{\circ}$ \\
\hline & & + & + & - & 2003 & Pediatric ICU (1), clinical-surgical (1) & $4^{\circ}, 6^{\circ}$ \\
\hline \multirow{2}{*}{ Clone 4} & 5 & + & - & - & 2003 & Pediatric ICU (1) & $4^{\circ}$ \\
\hline & & + & + & - & $2003 / 2004$ & Clinical-surgical (1), adult ICU (1)/ pediatric ICU (2) & $6^{\circ}, 3^{\circ}, 4^{\circ}$ \\
\hline \multirow[t]{4}{*}{ Clone 5} & 13 & - & + & - & 2003 & Clinical-surgical (1) & $5^{\circ}$ \\
\hline & & + & + & + & 2003 & Adult ICU (3) & $3^{\circ}$ \\
\hline & & + & + & + & 2004 & Adult ICU (3)/ clinical-surgical (2) & $3^{\circ} / 5^{\circ}, 6^{\circ}$ \\
\hline & & - & + & + & 2004 & Adult ICU (2)/ clinical-surgical (2) & $3^{\circ} / 5^{\circ}, 6^{\circ}$ \\
\hline Clone 6 & 2 & + & + & + & $2003 / 2004$ & Adult ICU (2) & $3^{\circ}$ \\
\hline \multirow[t]{3}{*}{ Clone 7} & 5 & + & + & + & 2005 & Pediatric ICU (1) & $4^{\circ}$ \\
\hline & & + & - & - & 2005 & Adult ICU (2) & $3^{\circ}$ \\
\hline & & + & + & + & 2005 & Neonatal ICU (1), adult ICU (1) & $3^{\circ}$ \\
\hline Clone 8 & 2 & + & + & - & 2005 & Adult ICU (1), pediatric ICU (1) & $3^{\circ}, 4^{\circ}$ \\
\hline \multirow[t]{2}{*}{ Clone 9} & 2 & + & + & + & 2005 & Urgency-emergency (1) & $1^{\circ}$ \\
\hline & & - & + & + & 2005 & Clinical-surgical (1) & $5^{\circ}$ \\
\hline \multirow[t]{2}{*}{ Clone 10} & 3 & + & + & - & 2006 & Clinical-surgical (1) & $6^{0}$ \\
\hline & & + & + & + & 2006 & Clinical-surgical (2) & $6^{\circ}$ \\
\hline \multirow[t]{2}{*}{ Clone 11} & 4 & + & + & - & 2006 & Clinical-surgical (2) & $5^{\circ}, 6^{\circ}$ \\
\hline & & - & + & - & 2006 & Clinical-surgical (2) & $6^{\circ}$ \\
\hline
\end{tabular}

a-, absence; +, presence; b, community infection. Adult ICU, Adult intensive-care unit; Neonatal ICU, Neonatal intensive-care unit; Pediatric ICU, Pediatric intensive-care. 


\section{DISCUSSION}

Although, in our study, E. coli was more frequently isolated than $K$. pneumoniae, ESBL production was more prevalent in K. pneumoniae, with a high prevalence (43.7\%) in the hospital environment, and especially in pediatric patients from the neonatal ICU. The high frequency of ESBLproducing bacteria in ICUs is expected due the great selective pressure resulting from the large use of antibiotics on ICU patients. High prevalence of ESBL among isolated $K$. pneumoniae had been detected in numerous studies as reviewed by Paterson and Bonomo. ${ }^{1}$ However, the prevalence of ESBL-positive K. pneumoniae and E. coli varies greatly among different geographical areas, with one of the highest reported rate (K. pneumoniae $30 \%$ to $60 \%$, E. coli $4.5 \%$ to $12 \%$ ) in Latin American countries, including Brazil. ${ }^{24,25}$

As previously reported in Juiz de Fora, Brazil, ${ }^{26}$ low prevalence of ESBL phenotype was detected in community isolates, independently of the bacteria species, $2.6 \%$ for $K$. pneumoniae and $0.4 \%$ for E. coli. Moreover, two of the five community-acquired cases reported healthcare contact (undergoing chemotherapy on day hospital) and may be healthcare associated infections.

Although the clinical impact of ESBLs is related to a combination of factors that rely more heavily on functional rather than structural characteristics, in terms of epidemiology or long-term effects of antibiotic use, identification of specific $\beta$-lactamases and/or their genes can play an important role. Among ESLB gene families, $b l a_{\text {TEM }}$ was the most prevalent in both E. coli and K. pneumoniae ESBL-producing isolates obtained from nosocomial and community infections. A very high prevalence of $b l a_{\text {СТХ-M }}(82.8 \%)$ was also detected among $K$. pneumoniae isolates, and $b l a_{\mathrm{SHV}}$ was present in $42.2 \%$ and $11.1 \%$ of K. pneumoniae and E. coli ESBL-producing isolates, respectively. $b l a_{\mathrm{TEM}}$ family genes are frequent among enterobacteria, ${ }^{1}$ but not all TEM enzymes can be considered ESBL, and sequencing is therefore necessary for allele identification..$^{13}$ Extra-intestinal infections caused by E. coli harbouring plasmid-encoded $b l a_{\mathrm{CTX}-\mathrm{M}}$ have been increasingly reported worldwide, from both developed and developing countries in the last decades. ${ }^{1,15,27-30}$ Moreover, while most of the SHV $\beta$-lactamases are ESBLs, it is known that the chromosomic bla $a_{\mathrm{SHV}-1}$ is highly prevalent in K. pneumoniae..$^{14}$

Genotyping using PFGE analysis of ESBL-producing $K$. pneumoniae revealed 23 different pulsotypes, consisting of 11 clones and 12 single patterns. Of the 11 clones, clone 5 was predominant and a persistent endemic clone in different wards and throughout the years. While multiclonal dissemination of ESBL-producing $K$. pneumoniae was found, no clonal dissemination of ESBL-producing $E$. coli was observed. Clonal dissemination suggests cross-transmission, which implies adopting precautionary measures of contact, including wearing aprons and gloves for contact with the colonized or infected patient, together with an efficient hy- gienization and antisepsis. Alternatively, the great genomic variability suggests strong selective pressure on bacterial populations, indicating the necessity of proper management of antibiotic therapy, particularly within healthcare units.

\section{CONCLUSION}

To sum up, the data obtained in this study showed that ESBL-producing isolates of E. coli and especially of Klebsiella spp. are essentially a nosocomial problem, and their dissemination to the community are not very significant. However, public health professionals must remain alert to the advancing issues associated with ESBLs to assist potential healthcare-associated and community outbreaks.

Genes $b l a_{\mathrm{TEM}}, b l a_{\mathrm{CTX}-\mathrm{M}}$, and $b l a_{\mathrm{SHV}}$ were detected in high frequency among ESBL-positive K. pneumoniae and E. coli isolates, occurring alone or in combination. The high prevalence of ESBL genes that are frequently found in conjugative plasmids and/or integrons may be considered a risk factor as they can be efficiently transferred within and between enterobacterial species.

Moreover, it was observed a great genomic variability in the ESBL-producing isolates of E. coli and Klebsiella spp., indicating a strong selective pressure of antimicrobials. However, it was also found that the polyclonal spread of strains might contribute to the proliferation of ESBL K. pneumoniae in the hospital and that endemic ESBL clone persisted throughout the years in the hospital. Finally, we have shown that molecular typing ESBL-producing K. pneumoniae was clinically relevant, given that patient-to-patient transmission of organisms harboring ESBLs, which were fundamental for infection control interventions, clearly occurs.

\section{REFERENCES}

1. Paterson DL, Bonomo RA. Extended-spectrum $\beta$-lactamases: a clinical update. Clin Microbiol Rev 2005; 18:657-86.

2. Bush K, Jacoby GA, Medeiros AA. A functional classification scheme for $\beta$-lactamases and its correlation with molecular structure. Antimicrob Agents Chemothey 1995; 39:1211-33.

3. Giske CG, Sundsfjord AS, Kahlmeter G et al. Redefining extended-spectrum $\beta$-lactamase: balancing science and clinical need. J Antimicrob Chemother 2009; 63:1-4.

4. Jacoby GA, Walsh KE, Walker VJ. Identification of extendedspectrum, AmpC, and carbapenem-hydrolyzing $\beta$-lactamases in Escherichia coli and Klebsiella pneumoniae by disk tests. J Clin Microbiol 2006; 44:1971-6.

5. Mena A, Plasencia V, García L et al. Characterization of a large outbreak by CTX-M-1-producing Klebsiella pneumoniae and mechanisms leading to in vivo carbapenem resistance development. J Clin Microbiob2006; 44:2831-7.

6. Rahal JJ. The role of carbapenems in initial therapy for serious Gram-negative infectious. Critical Care 2008; (12):2-7.

7. Poirel L, Decousser JW, Nordmann, P. Insertion sequence ISEcp1B is involved in expression and mobilization of the blaCTX-M $\beta$-lactamase gene. Antimicrob Agents Chemother 2003; 47:2938-45. 
8. Machado E, Cantón R, Baquero F et al. Integron content of extended-spectrum- $\beta$-lactamase-producing Escherichia coli strains over 12 years in a single hospital in Madrid, Spain. Antimicrob Agents Chemother 2005; 49:1823-9.

9. Slama TG. Gram-negative antibiotic resistance: there is a price to pay. Critical Care 2008; 12:S4.

10. ?

11. Paterson DL, Ko W-C, Gottberg A Von et al. International prospective study of Klebsiella pneumoniae bacteremia: implications of extended-spectrum $\beta$-lactamase production in nosocomial infections. Ann Intern Med 2004; 140:26-32.

12. Garcia DO, Doi Y, Szabo D et al. Multiclonal outbreak of Klebsiella pneumoniae producing extended-spectrum $\beta$-lactamase CTX-M-2 and novel variant CTX-M-59 in a neonatal intensive care unit in Brazil. Antimicrob Agents Chemother 2008; 52:1790-3.

13. Knothe $\mathrm{H}$, Shah $\mathrm{P}, \mathrm{Kramery} \mathrm{V}$ et al. Transferable resistance to cefotaxime, cefoxitin, cefamandole and cefuroxime in clinical isolates of Klebsiella pneumoniae and Serratia marcescens. Infection 1983;11:315-7.

14. Bradford, PA. Extended-spectrum $\beta$-lactamases in the $21^{\text {st }}$ century: characterization, epidemiology, and detection of this important resistance threat. Clin Microbiol Rev 2001; 14:933-51.

15. Paterson DL, Hujer KM, Hujer AM et al. Extended-spectrum $\beta$-lactamases in Klebsiella pneumoniae bloodstream isolates from seven countries: dominance and widespread prevalence of SHV- and CTX-M-type $\beta$-lactamases. Antimicrob Agents Chemother 2003; 47:3554-60.

16. Rodriguez-Baño J, Navarro MD, Romero L et al. Epidemiology and clinical features of infections caused by extended-spectrum beta-lactamase-producing Escherichia coli in non-hospitalized patients. J Clin Microbiol 2004; 42:1089-94.

17. Oteo J, Navarro C, Cercenado E et al. Spread of Escherichia coli strains with high-level cefotaxime and ceftazidime resistance between the community, long-term care facilities and hospital institutions. J Clin Microbiol 2006; 44:2359-66.

18. Mendonça N, Leitão J, Manageiro V et al. Antimicrobial Resistance Surveillance Program in Portugal; Caniça, M. Spread of extended-spectrum $\beta$-lactamase CTX-M-producing Escherichia coli clinical isolates in community and nosocomial environments in Portugal. Antimicrob Agents Chemother 2007; 51:1946-55.

19. Garner JS, Jarvis WR, Emori TG et al. CDC definitions isolated for nosocomial infections. Am J Infect Control 1988; 16:128-40.
20. Rodriguez-Baño, J, Navarro, MD, Romero, L et al. Epidemiology and clinical features of infections caused by extendedspectrum beta-lactamase-producing Escherichia coli in nonhospitalized patients. J Clin Microbiol 2004; 42:1089-94.

21. Clinical and Laboratory Standards Institute. (CLSI). Performance standards for antimicrobial disk susceptibility testing. Approved standard M2-A10. Clinical Laboratory Standards Institute, Wayne, PA, 2007.

22. Centers for Disease Control and Prevention. One-Day (24-28 h) Standardized Laboratory Protocol for Molecular Subtyping of Escherichia coli O157:H7, non-typhoidal Salmonella serotypes, and Shigella sonnei by Pulsed Field Gel Electrophoresis. In: PulseNet PFGE Manual http://www.cdc.gov/PulseNet/protocols/ecoli_salmonella_shigella_protocols.pdf.

23. Tenover F, Arbeit R, Goering $\mathrm{R}$ et al. Interpreting chromosomal DNA restriction patterns produced by pulsed-field gel electrophoresis: criteria for bacterial strain typing. J Clin Microbiol 1995; 33:2233-39.

24. Coque TM, Liver A, Pérez-Dias JC et al. Genes encoding TEM-4, SHV-2, and CTX-M-10 extended-spectrum $\beta$-lactamase are carried by multiple Klebsiella pneumoniae clones in a single hospital (Madrid, 1989 to 2000). Antimicrob Agents Chemother 2002; 46:500-10.

25. Winokur PL, Canton R, Casellas JM et al. Variations in the prevalence of strains expressing an extended-spectrum $\beta$-lactamases phenotype and characterization of isolates from Europe, the Americas, and the Western Pacific region. Clin Infec Dis 2001; 32:94-103.

26. Sader, HS, Gales, AC, Pfaller, MA et al. Pathogens frequency and resistance patterns in Brazilian hospitals: summary of results from three years of SENTRY antimicrobial surveillance program. Braz J Infect Dis 2001; 59:200-14.

27. Minarini LA, Gales AC, Palazzo IC et al. Prevalence of community-occurring extended spectrum $\beta$-lactamase-producing Enterobacteriaceae in Brazil. Curr Microbiol 2007; 54:335-41.

28. Nicolas-Chanoine, $\mathrm{MH}$, Blanco, J, Leflon-Guibout, $\mathrm{V}$ et al. Intercontinental emergence of Escherichia coli clone O25:H4-ST131 producing CTX-M-15. J Antimicrob Chemother 2008; 61:273-81.

29. Romero, L, López, L, Rodrigues-Baño, L et al. Long-term study of the frequency of Escherichia coli and Klebsiella pneumoniae isolates producing extended-spectrum $\beta$-lactamases. Clin Microbiol Infect 2005; 11:625-31.

30. Canton R, Coque TM. The CTX-M $\beta$-lactamase pandemic. Curr Opin Microbiol 2006; 466-75.

31. Lewis JS, Herrera M, Wickers B et al. First report of the emergence of CTX-M-type extended-spectrum $\beta$-lactamases (ESBLs) as the predominant ESBL isolated in a U.S. health care system. Antimicrob Agents Chemother 2007; 51:4015-21. 